\title{
Caspase Inhibition Prevents Tumor Necrosis Factor- $\alpha$-Induced Apoptosis and Promotes Necrotic Cell Death in Mouse Hepatocytes in Vivo and in Vitro
}

Hong-Min Ni, Mitchell R. McGill, Xiaojuan Chao, Benjamin L. Woolbright, Hartmut Jaeschke, and Wen-Xing Ding

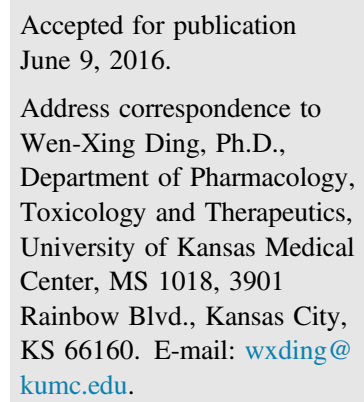

\begin{abstract}
How different cell death modes and cell survival pathways cross talk remains elusive. We determined the interrelation of apoptosis, necrosis, and autophagy in tumor necrosis factor (TNF)- $\alpha$ /actinomycin D (ActD) and lipopolysaccharide/D-galactosamine (GalN)-induced hepatotoxicity in vitro and in vivo. We found that TNF- $\alpha$ /ActD-induced apoptosis was completely blocked by a general caspase inhibitor ZVADfmk at 24 hours but hepatocytes still died by necrosis at 48 hours. Inhibition of caspases also protected mice against lipopolysaccharide/GalN-induced apoptosis and liver injury at the early time point, but this protection was diminished after prolonged treatment by switching apoptosis to necrosis. Inhibition of receptor-interacting protein kinase (RIP)1 by necrostatin 1 partially inhibited TNF- $\alpha / Z V A D$-induced necrosis in primary hepatocytes. Pharmacologic inhibition of autophagy or genetic deletion of Atg 5 in hepatocytes did not protect against TNF- $\alpha$ /ActD/ZVAD-induced necrosis. Moreover, pharmacologic inhibition of RIP1 or genetic deletion of RIP3 failed to protect and even exacerbated liver injury after mice were treated with lipopolysaccharide/GalN and a pan-caspase inhibitor. In conclusion, our results suggest that different cell death mode and cell survival pathways are closely integrated during TNF- $\alpha-$ induced liver injury when both caspases and NF- $\kappa B$ are blocked. Moreover, results from our study also raised concerns about the safety of currently ongoing clinical trials that use caspase inhibitors. (Am J Pathol 2016, 186: 2623-2636; http://dx.doi.org/10.1016/j.ajpath.2016.06.009)
\end{abstract}

The pathogenesis of many human diseases, including liver diseases, generally involves cellular dysfunction and cell death. A liver cell can die in many different ways, but caspase-dependent apoptosis and caspase-independent necrosis are thought to be the predominant cell death pathways that contribute to liver injury. ${ }^{1,2}$ Apoptosis can be activated by two distinct pathways: the intrinsic mitochondrial pathway and the extrinsic death-receptor pathway. In the liver, the activation of extrinsic death-receptor-mediated apoptotic pathway by tumor necrosis factor (TNF)- $\alpha$ and Fas ligand is one common pathway to cause acute liver injury. 1,2 TNF- $\alpha$ is a pleiotropic cytokine that is up-regulated in a number of stressful conditions that result in liver injury. One of the well-established animal models to study TNF- $\alpha-$ induced hepatocyte apoptosis and liver injury is
Supported in part by National Institute on Alcohol Abuse and Alcoholism grants R01 AA020518 (W.-X.D.) and R01 DK102142 (W.-X.D. and H.J.), National Center for Research Resources grant P20RR021940 (H.J.), National Institute of General Medical Sciences grant P20 GM103549 (H.J.), National Institutes of Environmental Health Sciences grant T32 ES007079 (M.R.M. and B.L.W.), National Institute of General Medical Sciences of the NIH Institutional Development Award (IDeA) P20 GM103418, and an award received in an internal Lied basic science grant program of the University of Kansas Medical Center (KUMC) Research Institute, with support from NIH Clinical and Translational Science Award grant UL1TR000001 (formerly UL1RR033179). The Electron Microscopy Research Laboratory is supported in part, by NIH COBRE grant 9P20GM104936. The JEOL JEM-1400 transmission electron microscope used in the study was purchased with funds from NIH grant S10RR027564.

Disclosures: RIP3 ${ }^{-/}$mice were a gift from Dr. Vishva Dixit (Genentech, San Francisco, CA). 
co-injection of mice with lipopolysaccharide (LPS) and D-galactosamine (GalN). ${ }^{3} \mathrm{TNF}-\alpha$ binding to TNF- $\alpha$ receptor I activates the assembly of the death-inducing signaling complex and results in the activation of caspase- 8 . Caspase- 8 further cleaves Bid and the truncated Bid translocates to mitochondria to trigger the mitochondrial intrinsic pathway, resulting in the release of mitochondrial cytochrome $c$ and second mitochondria-derived activator of caspase, which further amplifies the apoptotic signals to ensure apoptosis induction. . $^{1,4}$

In addition to apoptosis, hepatocytes can also die by necrosis, which is characterized by swollen cells, permeabilized plasma membrane and is often accompanied by inflammation in vivo. ${ }^{5}$ Although necrosis has previously been considered an uncontrolled cellular process without caspase activation, recent evidence indicates that necrosis can also be highly regulated, a process referred to as necroptosis or programed necrosis. Necroptosis is similar in nature to necrosis but is generally thought to be initiated by death receptor activation and mediated by the receptorinteracting protein kinase 1 (RIP1), RIP3 and its downstream mixed lineage kinase domain-like protein. ${ }^{6-8}$

Autophagy is a catabolic lysosomal degradation pathway, which plays a critical role in normal liver physiology and liver diseases. ${ }^{9}$ Autophagy involves the formation of doublemembrane autophagosomes that engulf intracellular proteins and organelles and then fuse with lysosomes to form autolysosomes, where enveloped cargo is degraded. Although under certain specific conditions autophagy may contribute to cell death, ${ }^{10}$ the liver basal autophagy seems to act as a cell survival function and is critical to maintain liver homeostasis. This notion is supported by the observations that genetic deletion of Atg5 or Atg7 in the mouse liver results in increased cell death and severe hepatomegaly and liver injury. ${ }^{11,12}$

Emerging evidence supports the idea that there is cross talk among autophagy, apoptosis, and necrosis. ${ }^{13,14}$ Autophagy protects cells against apoptosis and necrosis in the liver by maintaining healthy mitochondrial functions and inhibiting caspase-8 activation, ${ }^{15,16}$ whereas apoptosis suppresses autophagy via caspase-mediated cleavage of essential autophagy proteins. ${ }^{17}$ Moreover, apoptosis can also inhibit necroptosis by caspase- 8 - mediated cleavage and inactivation of both RIP1 and RIP3. ${ }^{8}$ Finally, inhibition of apoptosis by genetic deletion of caspase- 8 or Fas-associated protein with death domain (FADD) or pharmacologic inhibition of caspase- 8 promotes the formation of the RIP1-RIP3 necrosome to trigger necroptosis. ${ }^{6}$

Here, we determined the interrelation of apoptosis, necrosis, and autophagy in TNF- $\alpha$ /actinomycin D (ActD) and LPS/GalN-induced hepatotoxicity in vitro and in vivo. We found that pharmacologic inhibition of caspases blocked TNF- $\alpha /$ ActD- and LPS/GalN-induced apoptosis at an early time point but triggered necrosis after prolonged caspase inhibition. Although TNF- $\alpha /$ ActD decreased autophagy flux in hepatocytes, autophagy seemed not to be important in contributing to TNF- $\alpha /$ ActD-induced necrosis after caspase inhibition. Our results demonstrated that inhibition of caspase-mediated apoptosis can trigger necrosis, which raises concerns over the use of caspase inhibitors for the treatment of liver injury.

\section{Materials and Methods}

\section{Reagents}

Antibodies used include $\beta$-actin (catalog no. A5441) from Sigma-Aldrich (Indianapolis, IN); cleaved caspase 3 (catalog no. 9661L), poly(ADP-ribose) polymerase (catalog no. 9542), and RIP1 (catalog nol. 3493) from Cell Signaling (Danvers, MA); RIP3 (catalog no. 2283) from Prosci (Fort Collins, CO); Beclin 1 (catalog no. sc11427) from Santa Cruz Biotechnology (Santa Cruz, CA); high mobility group box 1 protein (HMGB1; catalog no. ab18256) from Abcam (Cambridge, United Kingdom); and anti-lymphocyte antigen B superfamily (Ly6B; catalog no. MCA771G) from AbD Serotec (Raleigh, NC). Horseradish peroxidase-conjugated secondary antibodies were from Jackson ImmunoResearch Laboratory (West Grove, PA). RIP1 inhibitor necrostatin, 7-Cl-O-Nec-1 (7-Nec1; 504297), and ZVAD-fmk (carbobenzoxy-valylalanyl-aspartyl-[O-methyl]-fluoromethylketone) were from Calbiochem (San Diego, CA). N-benzyloxycabonyl-Val Aspfluoromethyl ketone (ZVD)-fmk, a general caspase inhibitor, was from Epicept (San Diego, CA; catalog no. EP 1013). All other chemicals were from Sigma-Aldrich, Invitrogen (Carlsbad, CA), or Calbiochem unless otherwise stated.

\section{Animals}

Wild-type (WT) mice were maintained in a C57BL/6 background (The Jackson Laboratory, Bar Harbor, ME).

$\mathrm{RIP}^{-/-}$mice were generously provided by Dr. Vishva Dixit (Genentech, San Francisco, CA) as we described previously. ${ }^{18}$ All mice were housed in cages (five mice per cage) receiving a 12-hour light/dark cycle. Mice were injected intraperitoneally with $100 \mu \mathrm{g} / \mathrm{kg}$ LPS and $700 \mathrm{mg} / \mathrm{kg}$ GalN for 6 hours. For some experiments, after the injection of LPS/ GalN with or without $10 \mathrm{mg} / \mathrm{kg}$ 7-Nec1 (i.p.) for 3 hours, the mice were further given $10 \mathrm{mg} / \mathrm{kg}$ ZVD i.p. for another 3 or 21 hours before the mice were sacrificed. Atg5 Flox/Flox mice (C57BL/6/129) were generated by Dr. N. Mizushima (University of Tokyo, Tokyo, Japan) and were backcrossed with C57BL/6 for another four generations before further crossing them with Albumin-Cre mice (C57BL/6; The Jackson Laboratory) as described previously. ${ }^{19}$ All procedures were performed according to the guidelines and approved by the Institutional Animal Care and Use Committee of the University of Kansas Medical Center.

\section{Primary Hepatocyte Culture and Cell Death Analysis}

Murine hepatocytes were isolated by a retrograde, nonrecirculating perfusion of livers with $0.05 \%$ collagenase 
type IV (Sigma-Aldrich) as described previously. ${ }^{20}$ Cells were cultured in William's medium $\mathrm{E}$ with $10 \%$ fetal bovine serum but no other supplements for 2 hours for attachment. Cells were then cultured in the same medium without serum overnight before treatment. All cells were maintained in a $37^{\circ} \mathrm{C}$ incubator with $5 \% \mathrm{CO}_{2}$.

\section{Immunoblot Assay}

Cells were washed in phosphate-buffered saline and lyzed in RIPA buffer. Twenty micrograms of protein from each sample were separated by SDS-PAGE and transferred to polyvinylidene difluoride membranes. The membranes were stained with primary antibodies, followed by secondary horseradish peroxidase-conjugated antibodies. The membranes were further developed with SuperSignal West Pico chemiluminescent substrate (Thermo Fisher Scientific, Rockford, IL).

\section{Microscopy for Cell Death and Autophagy}

Apoptotic and necrotic death were determined as previously described $^{20}$ at various time points after the treatment. Briefly, cells were costained with $5 \mu \mathrm{g} / \mathrm{mL}$ Hoechst 33342 and $1 \mu \mathrm{g} / \mathrm{mL}$ propidium iodide (PI) for 10 minutes. Both fluorescence and phase-contrast images were obtained via a fluorescence microscope (Nikon Eclipse 200; Nikon, Melville, NY). Cells stained with Hoechst 33342 showing condensed and/or fragmented nuclei were considered apoptotic, whereas cells stained with PI but showing no signs of nuclear condensation and/or fragmentation were considered necrotic. Viable cells were PI negative and did not show apoptotic nuclear changes by Hoechst staining.

To examine autophagy, primary hepatocytes were seeded in a 12-well plate $\left(2 \times 10^{5}\right.$ in each well $)$ and infected with adenovirus-red fluorescent protein (RFP)-green fluorescent protein (GFP)-LC3 (5 multiplicity of infection) overnight. After treatment, cells were fixed with $4 \%$ paraformaldehyde in phosphate-buffered saline and kept at $4{ }^{\circ} \mathrm{C}$ for microscopy. Fluorescence images were acquired under a Nikon Eclipse 200 fluorescence microscope with MetaMorph software version 7.7.0.0 (Molecular Devices, Sunnyvale, CA). For the immunostaining assay, cells were immunostained with the anti-HMGB1 antibody followed by cyanine 3-conjugated secondary antibody as previously described. ${ }^{20}$

\section{Histology and Immunohistochemistry}

Paraffin-embedded liver sections were stained with hematoxylin and eosin for pathologic analysis of cell death. Immunostaining for Ly6B-positive neutrophils was performed as described previously. ${ }^{21}$ The numbers of Ly6B-positive cells were counted from 20 different fields $(\times 40)$ in a blinded fashion (X.C.). Terminal deoxynucleotidyl transferase dUTP nick end labeling (TUNEL) staining was performed as described previously. ${ }^{18}$

\section{Electron Microscopy}

Cells were fixed with $2.5 \%$ glutaraldehyde in $0.1 \mathrm{~mol} / \mathrm{L}$ phosphate buffer ( $\mathrm{pH} 7.4$ ), followed by $1 \% \mathrm{OsO}_{4}$. After dehydration, thin sections were stained with uranyl acetate and lead citrate for observation under a JEM 1011CX electron microscope (JEOL, Tokyo, Japan). Images were acquired digitally. The average number of autophagosomes from each cell was determined from a randomly selected pool of 15 to 20 fields under each condition.

\section{Real-Time Quantitative PCR}

RNA was extracted from mouse liver using Trizol (Invitrogen) and reverse transcribed into cDNA by RevertAid Reverse Transcriptase (Fermentas, Hanover, MD). Realtime PCR was performed on a Bio-Rad CFX384 real-time PCR detection system using iTaq Universal SYBR Green Supermix (Bio-Rad, Hercules, CA). Expression of $\beta$-actin, TNF- $\alpha$, and IL-1 $\beta$ was quantified using real-time quantitative PCR analysis. Primers sequences were as follows: $\beta$-actin forward, 5'-TGTTACCAACTGGGACGACA-3', and $\beta$-actin reverse, $5^{\prime}$-GGGGTGTTGAAGGTCTCAAA- $3^{\prime}$; TNF- $\alpha$ forward, $5^{\prime}$-CGTCAGCCGATTTGCTATCT- $3^{\prime}$, and TNF- $\alpha$ reverse, 5'-CGGACTCCGCAAAGTCTAAG-3'; and IL- $1 \beta$ forward, $5^{\prime}$-GCCCATCCTCTGTGACTCAT- $3^{\prime}$, and IL-1 $\beta$ reverse, $5^{\prime}$-AGGCCACAGGTATTTTGTCG-3'

\section{Statistical Analysis}

Experimental data were subjected to $t$-test or one-way analysis of variance analysis with Scheffé's post hoc test when appropriate. $P<0.05$ was considered significant.

\section{Results}

\section{Inhibition of Caspases Switches TNF- $\alpha$ /ActD-Induced Apoptosis to Necrosis in Primary Cultured Mouse Hepatocytes}

To determine the role of caspase activation in cell death induced by TNF- $\alpha$ in hepatocytes, we first examined whether ZVAD, a general caspase inhibitor, could provide any protection from TNF- $\alpha$-induced apoptosis. TNF$\alpha$-induced cell death was noticeable in 6 hours, and almost $90 \%$ of cells died from apoptosis at 24 hours, characterized by the typical nuclear fragmentation by Hoechst 33342 staining (Figure 1A). The general caspase inhibitor ZVAD significantly suppressed apoptosis for an even longer duration, up to 48 hours (Figure 1, A and B). To determine whether inhibition of caspase by ZVAD triggers necrosis, cells were stained with PI, a cell-permeable dye that only stains cells when their plasma membranes are broken or permeabilized, in particular, during necrotic cell death. We found that TNF- $\alpha$-treated hepatocytes were severely shrunken, had membrane blebbing, and detached from the 

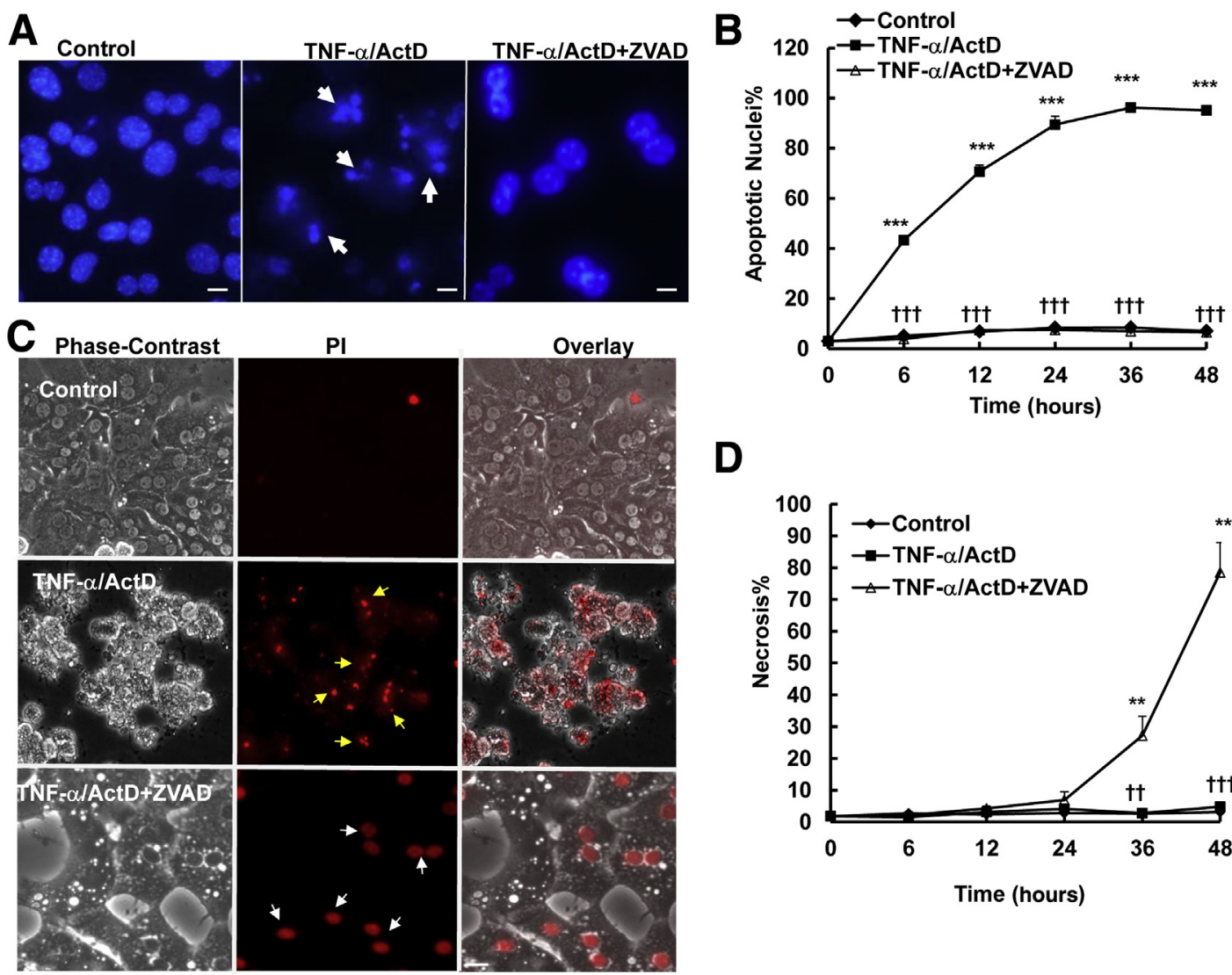

D

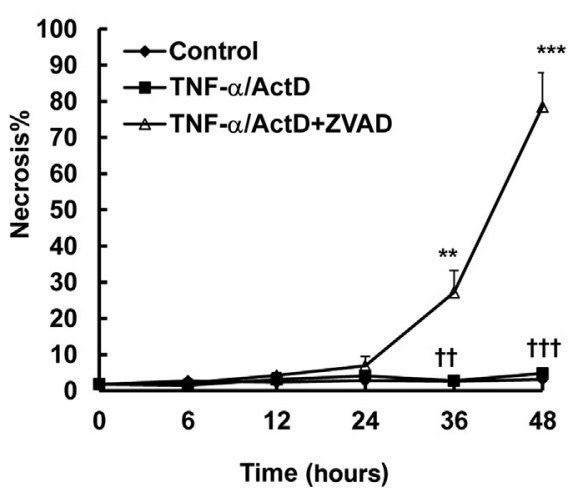

Figure 1 Inhibition of caspase by ZVAD switches TNF- $\alpha$ /ActD-induced apoptosis to necrosis in cultured hepatocytes. Primary mouse hepatocytes were either untreated (control) or treated with $10 \mathrm{ng} / \mathrm{mL}$ TNF- $\alpha$ plus $0.1 \mu \mathrm{g} / \mathrm{mL}$ ActD, $50 \mu \mathrm{mol} / \mathrm{L}$ TNF- $\alpha /$ ActD plus ZVAD. A: Hepatocytes were treated as described above for 6 hours and stained with $1 \mu \mathrm{g} / \mathrm{mL}$ Hoechst 33342, followed by fluorescence microscopy. Representative images of hepatocyte nuclei are shown. Arrows denote apoptotic fragmented nuclei. B: Quantification of apoptotic nuclei after the cells were treated as described for different time points. C: Hepatocytes were treated as in panel A for 24 hours and stained with $1 \mu \mathrm{g} / \mathrm{mL}$ PI, followed by fluorescence microscopy. Representative phase-contrast, PI, and overlaid hepatocyte images are shown. Yellow arrows denote the fragmented PI-positive nuclei (secondary necrosis), and white arrows denote the PI-positive intact nuclei (necrosis). D: Quantification of necrosis after the cells were treated as described for different time points. Data are expressed as means \pm SEM. $n=3$ independent experiments, and more than 100 cells counted in each experiment. ${ }^{* *} P<0.01,{ }^{* * *} P<0.001$ versus control; ${ }^{\dagger \dagger} P<0.01,{ }^{\dagger \dagger \dagger} P<0.001$ versus TNF- $\alpha$ /ActD. One-way analysis of variance analysis with Scheffé's post hoc test. Scale bar: $20 \mu \mathrm{m}(\mathbf{A}$ and $\mathbf{C})$. ActD, actinomycin D; PI, propidium iodide; TNF- $\alpha$, tumor necrosis factor- $\alpha$.

culture plate by 24 hours. Almost all of the hepatocytes had fragmented nuclei that also stained positive with PI due to the secondary necrosis in the culture conditions. To our surprise, although ZVAD completely inhibited TNF$\alpha$-induced apoptosis, cells died from necrosis characterized by cell swelling and intact PI-positive nuclei at the later stage (36 to 48 hours) (Figure 1, C and D). During necrosis, HMGB1, a nuclear protein that binds to chromatin, is released from the nuclei. ${ }^{22}$ HMGB 1 is exclusively located in the nuclei as demonstrated by its colocalization with nuclear Hoechst 33342 staining in control nontreated hepatocytes. However, almost $80 \%$ of hepatocytes had lost the nuclear staining of HMGB1 in 48 hours after TNF- $\alpha / A c t D / Z V A D$ treatment, indicating that TNF- $\alpha / A c t D / Z V A D$ treatment induces HMGB1 release (Figure 2, A and B). Electron microscopy studies further revealed that TNF- $\alpha / \mathrm{ActD} /$ ZVAD-treated cells had large cellular vacuoles (Figure 2C) and disrupted organelles such as mitochondria (Figure 2C). These results clearly indicate that inhibition of caspases by ZVAD suppresses TNF- $\alpha$-induced apoptosis, but cells still die by necrosis after prolonged treatment (36 to 48 hours) in primary mouse hepatocytes.

Antioxidants and JNK Inhibitor Do Not Protect against TNF- $\alpha$ /ActD/ZVAD-Induced Necrosis in Primary Cultured Mouse Hepatocytes

To determine the contribution of reactive oxygen species to TNF- $\alpha$ /ActD/ZVAD-induced necrosis in hepatocytes, we first examined whether three antioxidants: MnTBAP, a potent superoxide dismutase mimetic, deferoxamine, an iron chelator, and catalase, an enzyme that detoxifies hydrogen peroxide to water and oxygen, could provide any protection against TNF- $\alpha /$ ActD/ZVAD-induced necrosis in hepatocytes. We found that TNF- $\alpha /$ ActD/ZVAD induced necrosis to the same extent with or without the presence of these antioxidants (Figure 3). We previously showed that inhibition of c-Jun N-terminal kinase (JNK) by a small molecule 

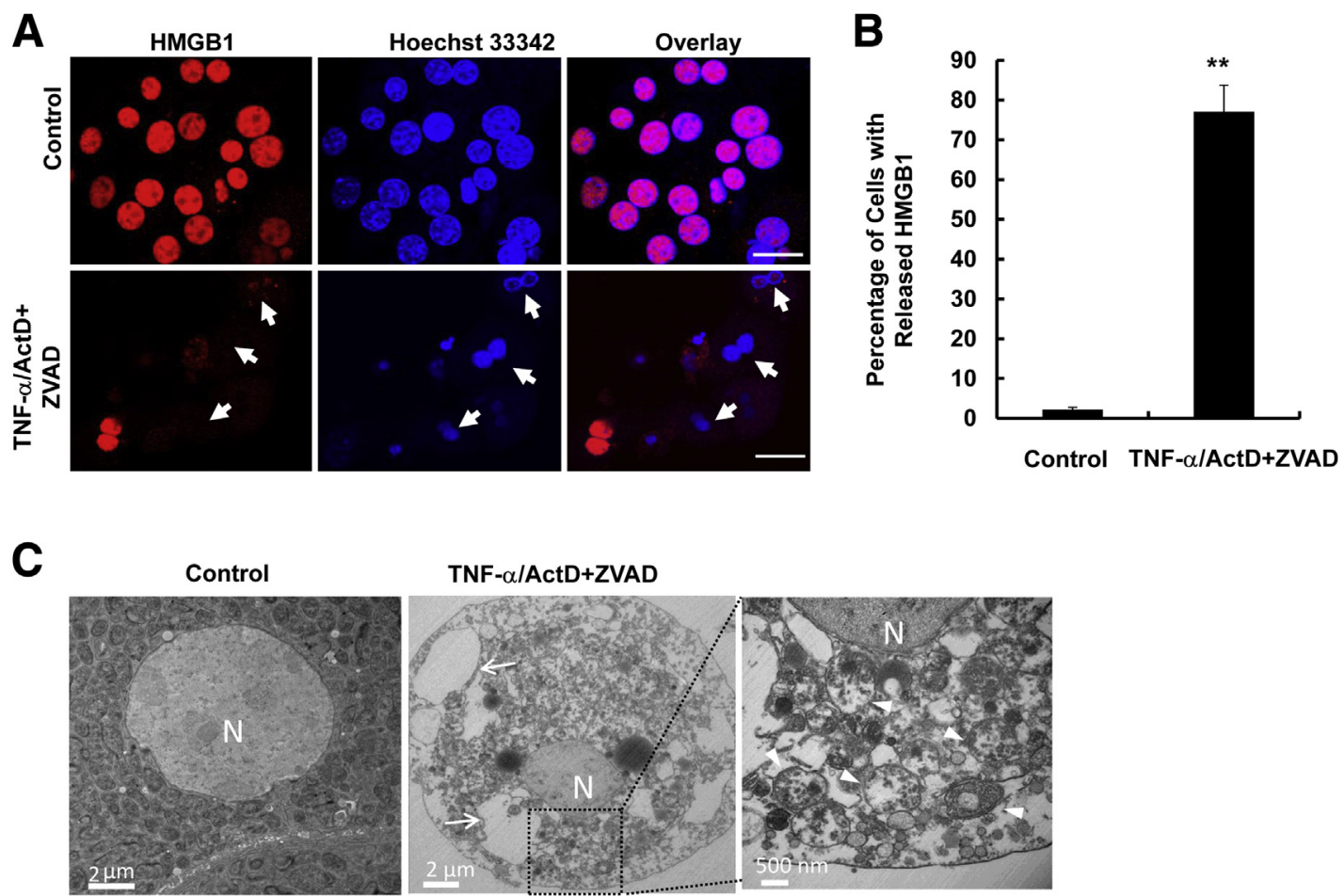

Figure 2 TNF- $\alpha /$ ActD + ZVAD treatment induces HMGB1 nuclear release and disruption of cellular organelles. Primary mouse hepatocytes were either untreated (control) or treated with $10 \mathrm{ng} / \mathrm{mL} \mathrm{TNF}-\alpha+0.1 \mu \mathrm{g} / \mathrm{mL}$ ActD $+50 \mu \mathrm{mol} / \mathrm{L}$ ZVAD for 48 hours. A: Hepatocytes were fixed and immunostained for HMGB1 and treated as described above for 6 hours and stained with $1 \mu \mathrm{g} / \mathrm{mL}$ Hoechst 33342, followed by fluorescence microscopy. Representative images of hepatocyte nuclei are shown. Arrows denote apoptotic fragmented nuclei. B: Quantification of apoptotic nuclei after the cells were treated as described for different time points. C: Cells were treated as in panel A for 48 hours and further processed for EM analysis. Representative EM images are shown. Right panel is an enlarged image from boxed area. Arrows indicate large cellular vacuoles; arrowheads, damaged mitochondria. Data are expressed as means \pm SEM. $n=3$ independent experiments, and more than 100 cells counted in each experiment. ${ }^{*} P<0.01$ versus control. One-way analysis of variance analysis with Scheffé's post hoc test. Scale bars: $=20 \mu \mathrm{m}(\mathbf{A}) ; 2 \mu \mathrm{m}$ (C, left and center panels); $500 \mathrm{~nm}$ (C, right panel). ActD, actinomycin D; EM, electron microscopy; HMGB, high mobility group box 1 protein; N, nucleus; TNF- $\alpha$, tumor necrosis factor- $\alpha$.

JNK inhibitor SP600125 could significantly inhibit TNF$\alpha$-induced apoptosis in hepatocytes. ${ }^{23}$ However, we found that SP600125 could not protect against TNF- $\alpha / A c t D /$ ZVAD-induced necrosis (Figure 3). These results indicate that reactive oxygen species and JNK are not essential for TNF- $\alpha /$ ActD/ZVAD-induced necrosis in hepatocytes.

\section{TNF- $\alpha /$ ActD/ZVAD Does Not Induce Autophagic Cell Death in Primary Cultured Mouse Hepatocytes}

We were not able to collect enough protein for immunoblotting from TNF- $\alpha / \mathrm{ActD}$-treated cells in 24 hours, because almost all of the hepatocytes were dead by apoptosis and secondary necrosis. Therefore, Western blot analysis was performed using cells that were treated with TNF- $\alpha /$ ActD in the presence or absence of ZVAD for 6 hours. As expected, we found that TNF- $\alpha /$ ActD induced caspase-3 cleavage, which was completely suppressed by ZVAD. Interestingly, we found that TNF- $\alpha$ also induced cleavage of Beclin 1, an essential autophagy protein that is required for the formation of autophagosomes. ZVAD completely blocked TNF- $\alpha /$ ActD-induced Beclin 1 cleavage, suggesting that TNF- $\alpha /$ ActD-induced Beclin 1 cleavage depends on caspase activation. There was a marked decrease of both LC3-II and p62 in TNF- $\alpha /$ ActD-treated cells likely due to increased apoptosis, which was inhibited by ZVAD (Figure 4A). To determine autophagic flux, hepatocytes were first infected with adenovirus-RFP-GFPLC3 for 24 hours, followed by TNF- $\alpha /$ ActD/ZVAD treatment. After autophagosomes fuse with lysosomes, the RFP signals are relatively stable, whereas the GFP signals are quenched due to the acidic environment in the autolysosomes. ${ }^{24}$ Therefore, an increased number of RFP-LC3 (red only) puncta reflects increased autophagic flux. We found that both the number of yellow puncta (RFP-GFP-LC3 puncta) and RFP-LC3 puncta (red only) was significantly

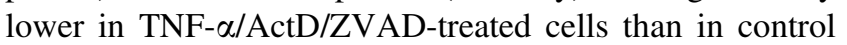
cells, suggesting that TNF- $\alpha /$ ActD/ZVAD decreases autophagic flux in hepatocytes (Figure 4, A-C). No difference was found for the percentage of RFP-LC3 puncta of the total LC3 puncta between TNF- $\alpha /$ ActD/ZVAD-treated and control cells, indicating that TNF- $\alpha / A c t D / Z V A D$ treatment may not affect the maturation of autophagosomes (such as the fusion of autophagosomes with lysosomes) (Figure 4D). The decreased number of yellow puncta in TNF- $\alpha / \mathrm{ActD} /$ ZVAD-treated cells compared with the control cells suggests that TNF- $\alpha /$ ActD/ZVAD may inhibit autophagy at the early autophagosome formation stage. 
A
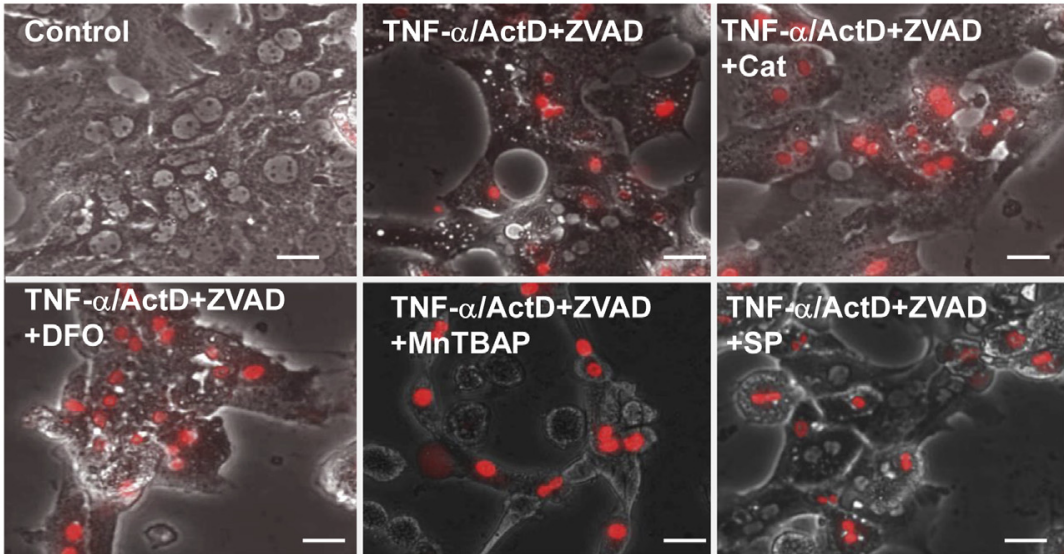

B

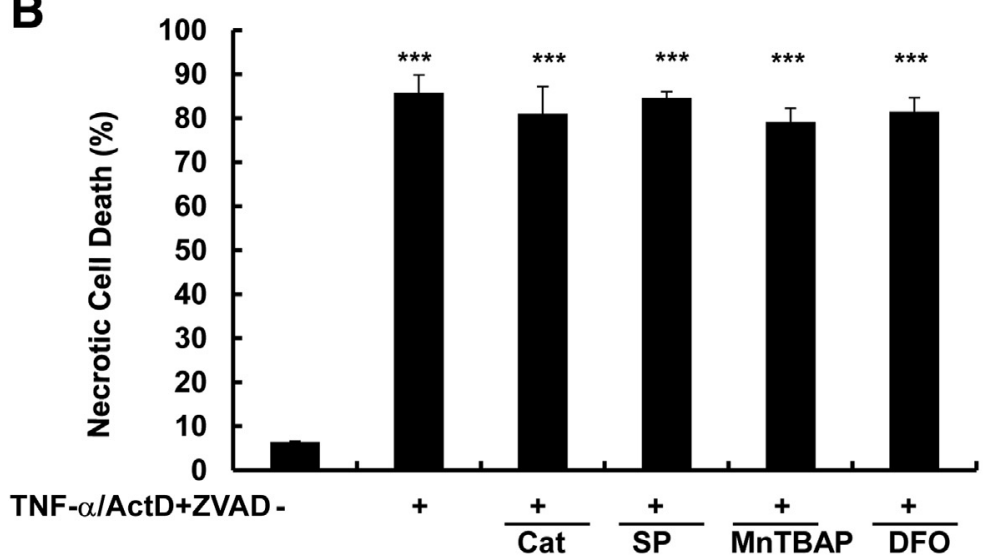

Figure 3 Antioxidants and JNK inhibitor do not protect against TNF- $\alpha /$ ActD +ZVAD-induced necrosis in hepatocytes. Primary mouse hepatocytes were either untreated (control) or treated with $10 \mathrm{ng} / \mathrm{mL}$ TNF- $\alpha+0.1 \mu \mathrm{g} / \mathrm{mL}$ ActD $+50 \mu \mathrm{mol} / \mathrm{L}$ ZVAD for 48 hours in the presence or absence of $1000 \mathrm{U} / \mathrm{mL}$ Cat, $1 \mathrm{mmol} / \mathrm{L} \mathrm{MnTBAP,} 5 \mathrm{mmol} / \mathrm{L} \mathrm{DFO}$, and $25 \mu \mathrm{mol} / \mathrm{L}$ SP6000125. A: Representative phase-contrast and PI staining overlaid images of hepatocytes. B: Quantification of the PI-positive necrotic cells. Data are expressed as means \pm SEM. $n=3$ independent experiments, and more than 100 cells counted in each experiment. ${ }^{* *} P<0.001$ versus control. One-way analysis of variance analysis with Scheffé's post hoc test. Scale bar $=20 \mu \mathrm{m}$. ActD, actinomycin D; Cat, catalase; DF0, deferoxamine; JNK, c-Jun N-terminal kinase; PI, propidium iodide; TNF- $\alpha$, tumor necrosis factor- $\alpha$.
We next determined the viability of cells treated with TNF- $\alpha /$ ActD/ZVAD in the presence of wortmannin or chloroquine. Wortmannin inhibits autophagy at the early autophagosome formation step by inhibiting phosphatidylinositol 3 kinase activity, and chloroquine disrupts the functions of autolysosomes by increasing lysosomal $\mathrm{pH}^{24,25}$ Neither wortmannin nor chloroquine affected TNF- $\alpha / \mathrm{ActD} /$ ZVAD-induced necrosis (Figure 5, A and B). To determine whether genetic blocking of autophagy in hepatocytes affects TNF- $\alpha / A c t D / Z V A D-i n d u c e d$ cell death, we isolated hepatocytes from liver-specific Atg 5 knockout (KO) mice as we reported previously. ${ }^{19}$ We found that more than $80 \%$ of Atg5-deficient hepatocytes died by necrosis after TNF- $\alpha /$ ActD/ZVAD for 48 hours (Figure 5, C and D), which is comparable with the WT cells (Figure 5B). Taken together, these results indicate that TNF- $\alpha / A c t D / Z V A D-i n d u c e d ~ n e-$ crosis is not autophagic cell death.

\section{TNF- $\alpha$ /ActD/ZVAD-Induced Necrosis in Primary Cultured Mouse Hepatocytes Involves RIP1}

We next determined whether RIP1 activity would be

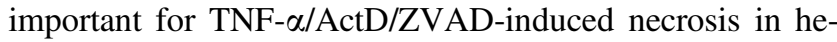
patocytes. We found that TNF- $\alpha /$ ActD treatment induced
RIP1 cleavage, which was completely blocked by ZVAD. These results are in agreement with previous reports that caspases can cleave RIP1 and in turn block RIP1-mediated necropotosis (Figure 6A). ${ }^{8} \mathrm{We}$ found that necrostatin, a small molecule inhibitor of RIP1 kinase activity, partially but significantly inhibited TNF- $\alpha$ /ActD/ZVAD-induced necrosis based on the number of PI-positive cells (Figure 6, B and C). These results suggest that TNF- $\alpha / \mathrm{ActD} /$ ZVAD-induced necrosis may depend partially on RIP1 in primary cultured hepatocytes.

\section{ZVD Inhibits LPS/GalN-Induced Apoptosis at the Early} Phase but Increases Necrosis and Causes Liver Injury at the Late Phase in Mice

Because we observed that inhibition of caspase could switch TNF- $\alpha$ /ActD-induced apoptosis to necrosis in primary cultured mouse hepatocytes, we next determined whether inhibition of caspase-mediated apoptosis could also induce necrosis and liver injury in vivo. Liver injury was induced by GalN and LPS, which results from GalN-mediated sensitization of hepatocytes to LPS-induced TNF- $\alpha$ production by Kupffer cells. LPS/GalN treatment significantly increased serum alanine aminotransferase (ALT) levels in 


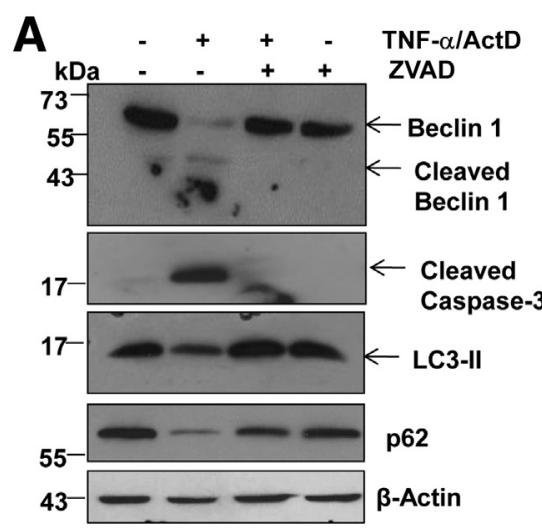

B

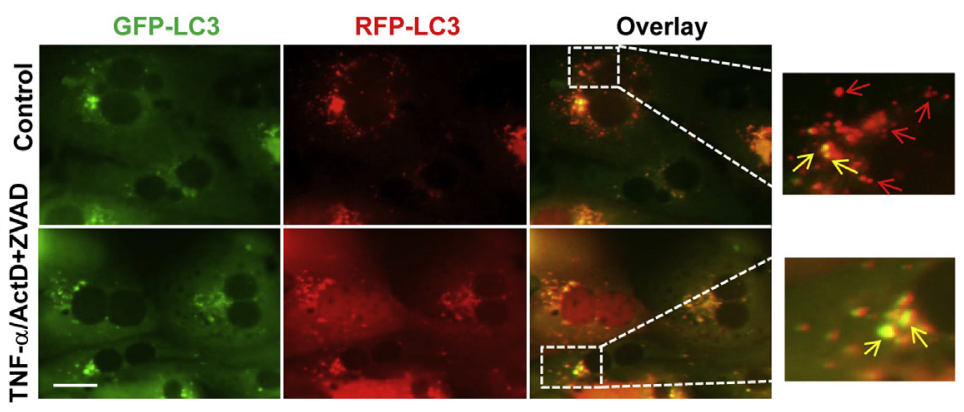

C

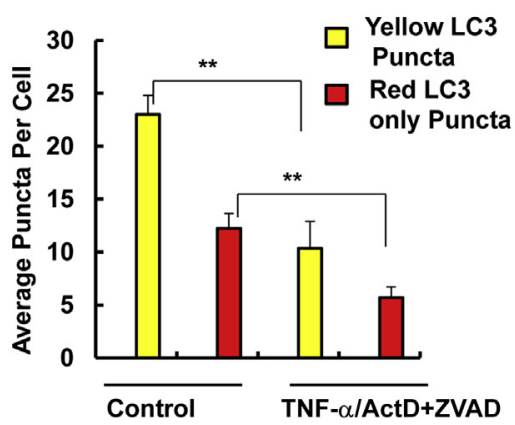

D

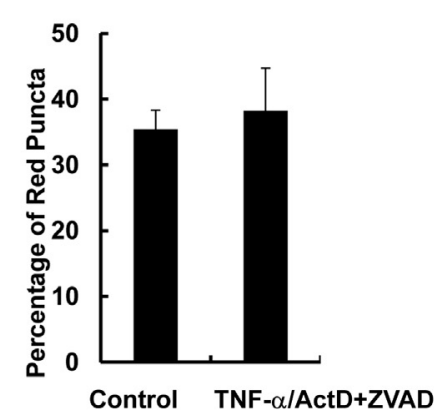

Figure $4 T \mathrm{TNF}-\alpha / A c t D+Z V A D$ does not induce autophagic flux in hepatocytes. Primary mouse hepatocytes were either untreated (control) or treated with $10 \mathrm{ng} / \mathrm{mL}$ TNF- $\alpha+0.1 \mu \mathrm{g} / \mathrm{mL}$ ActD for 6 hours or $10 \mathrm{ng} / \mathrm{mL}$ TNF- $\alpha+0.1 \mu \mathrm{g} / \mathrm{mL}$ ActD $+50 \mu \mathrm{mol} / \mathrm{L}$ ZVAD for 24 hours. A: Total cell lysates were subjected to Western blot analysis. All of the gels have been run under the same experimental conditions. Primary mouse hepatocytes were first infected with Ad-RFP-GFPLC3 (5 multiplicity of infection) for 24 hours, and the cells were then either untreated (control) or treated with $10 \mathrm{ng} / \mathrm{mL} \mathrm{TNF}-\alpha+0.1 \mu \mathrm{g} / \mathrm{mL} \mathrm{ActD}+50 \mu \mathrm{mol} /$ L ZVAD for 24 hours. B: Representative fluorescence images of hepatocytes. Right panels are enlarged images from the boxed areas in the left panels. Yellow arrows indicate RFP-GFP-LC3 puncta; red arrows indicate RFP-LC3 puncta only. C and D: Quantification of total yellow- and red-only puncta per cell (C) and percentage of the red puncta (D). Data are expressed as means \pm SEM. $n=3$ independent experiments, and more than 20 cells counted in each experiment. ${ }^{*} P<0.01$ versus control. One-way analysis of variance analysis with Scheffé's post hoc test. Scale bar $=20 \mu \mathrm{m}(\mathbf{B})$. ActD, actinomycin D; Ad, adenovirus; GFP, green fluorescent protein; RFP, red fluorescent protein; TNF- $\alpha$, tumor necrosis factor- $\alpha$.

6 hours, which was completely blocked by ZVD, a general caspase inhibitor similar to ZVAD that is more hydrophilic, and thus alleviates the need for high concentrations of vehicle solvents ${ }^{26}$ (Figure 7A). Indeed, LPS/GalN treatment increased caspase-3 activity 25-fold compared with the control saline-treated mice, and that effect was completely blocked by ZVD (Figure 7B). These results indicate that ZVD inhibits LPS/GalN-induced caspase-mediated apoptosis and liver injury at 6 hours. None of the mice survived after LPS/GalN treatment for 24 hours. As expected, ZVD treatment markedly improved mouse survival after LPS/GalN treatment for 24 hours (seven of eight mice survived). However, to our surprise, serum ALT levels were significantly elevated in LPS/GalN/ZVD-treated mice at 24 hours, despite the fact that no caspase-3 activation was detected in these mice (Figure 7, A-C). These results suggest inhibition of caspases triggers caspase-independent cell death and liver injury after prolonged treatment with LPS/GalN. Histologic analysis from hematoxylin and eosin staining of liver tissues revealed that hepatic hemorrhage and the number of fragmented nuclei increased in LPS/ GalN-treated mouse livers at 6 hours, whereas the liver tissues looked almost completely normal in mice that were treated with LPS/GalN together with ZVD (Figure 7D). However, increased focal necrosis characterized by swollen hepatocytes and infiltrated inflammatory cells were readily observed after the mice were treated with LPS/GalN together with ZVD for 24 hours (Figure 7D). LPS/GalN treatment also increased the numbers of TUNEL-positive nuclei at 6 hours, which were inhibited by ZVD. However, after prolonged treatment with LPS/GalN together with ZVD for 24 hours, the number of TUNEL-positive cells markedly increased. The pattern of TUNEL staining was diffuse in the mice that were treated with LPS/GalN together with ZVD, including staining in the cytostol, which is in stark contrast to the nuclear staining pattern in LPS/GalNtreated mice at 6 hours (Figure 7D). The diffuse TUNEL staining reflects the random DNA breakage and release of DNA fragments from the nucleus, which often occurs in necrotic but not apoptotic cells. ${ }^{27}$ The hepatic protein levels 

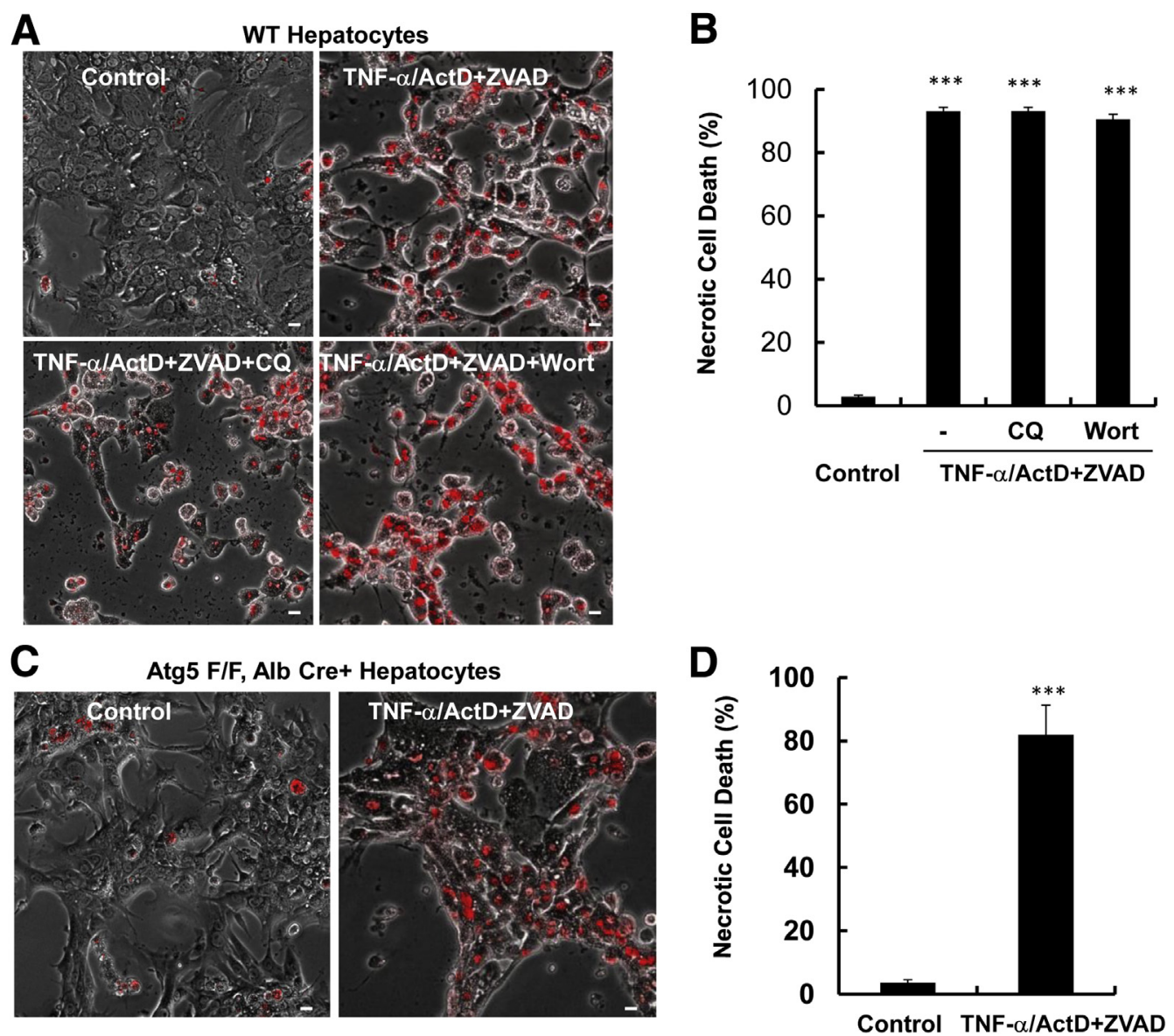

Figure 5 TNF- $\alpha / A c t D+Z V A D$ does not induce autophagic cell death in hepatocytes. Primary mouse hepatocytes were either untreated (control) or treated with $10 \mathrm{ng} / \mathrm{mL} \mathrm{TNF}-\alpha+0.1 \mu \mathrm{g} / \mathrm{mL}$ ActD $+50 \mu \mathrm{mol} / \mathrm{L} \mathrm{ZVAD}$ in the presence or absence of $0.2 \mu \mathrm{mol} / \mathrm{L}$ Wort or $20 \mu \mathrm{mol} / \mathrm{L}$ CQ for 48 hours. A: Representative phase-contrast and PI staining overlaid images of hepatocytes. B: Quantification of the PI-positive necrotic cells. C: Primary hepatocytes were isolated from Atg5 F/F, Alb $\mathrm{Cre}^{+}$mice and were treated as in panel A. Representative phase-contrast and PI staining overlaid images of hepatocytes are shown. D: Quantification of the PI-positive necrotic cells. Data are expressed as means \pm SEM. $n=3$ independent experiments, and more than 100 cells counted in each experiment. ${ }^{* *} P<0.001$ versus control. One-way analysis of variance analysis with Scheffé's post hoc test. Scale bar $=20 \mu \mathrm{m}$. ActD, actinomycin D; Alb, Albumin; Atg5 F/F, Atg5 Flox/Flox; CQ, chloroquine; PI, propidium iodide; TNF- $\alpha$, tumor necrosis factor- $\alpha$; Wort, wortmannin; WT, wild-type.

of RIP1, RIP3, and Beclin 1 decreased markedly after mice were treated with LPS/GalN for 6 hours and that effect was inhibited by ZVD in both 6 and 24 hours of treatment (Figure 7E). These results suggest that RIP1, RIP3, and Beclin 1 are cleaved by caspases during apoptosis in LPS/ GalN-treated mouse livers. Taken together, these data indicate that inhibition of caspases suppresses LPS/GalNinduced apoptosis and liver injury at the early phase but that liver injury still occurs at the late phase through alternative necrotic cell death.

Pharmacologic Inhibition of RIP1 or Genetic Deletion of RIP3 Exacerbates LPS/GalN/ZVD-Induced Liver Injury

Because RIP1 and RIP3 are important regulators for necropotosis, we hypothesized that inhibition of RIP1 or RIP3 would be protective against LPS/GalN/ZVD-induced liver injury at the late phase. To our surprise, 7-Nec1, a specific RIP1 kinase inhibitor, did not inhibit but further increased serum ALT levels after LPS/GalN/ZVD treatment (Figure 8A). No changes in caspase-3 activities were found among all of the groups, suggesting that LPS/GalN/ ZVD-induced liver injury is independent of caspases (Supplemental Figure S1). Unlike LPS/GalN/ZVD treatment that leads to necrotic cell death in the liver (Figure 7D), in the presence of 7-Nec1, hepatocytes had fragmented nuclei visible in the hematoxylin and eosin staining (Figure 8C). Furthermore, TUNEL staining signals were mainly enriched in the nuclei (Figure 8C), which is in contrast to the cytosolic staining pattern in hepatocytes that were treated with LPS/ GalN/ZVD (Figure 7C). These results suggest that 7-Nec1 may switch LPS/GalN/ZVD-induced necrosis to caspaseindependent apoptosis. Similar to inhibition of RIP1 by 7-Nec1, RIP3 KO mice also had increased serum ALT levels compared with WT mice after LPS/GalN/ZVD treatment for 24 hours (Figure 8B). Hepatocytes also had fragmented nuclei (Figure 8C), and RIP3 KO hepatocytes had nuclear but not cytosolic TUNEL-positive staining after LPS/GalN/ZVD treatment (Figure 8C). We also determined the infiltration of 

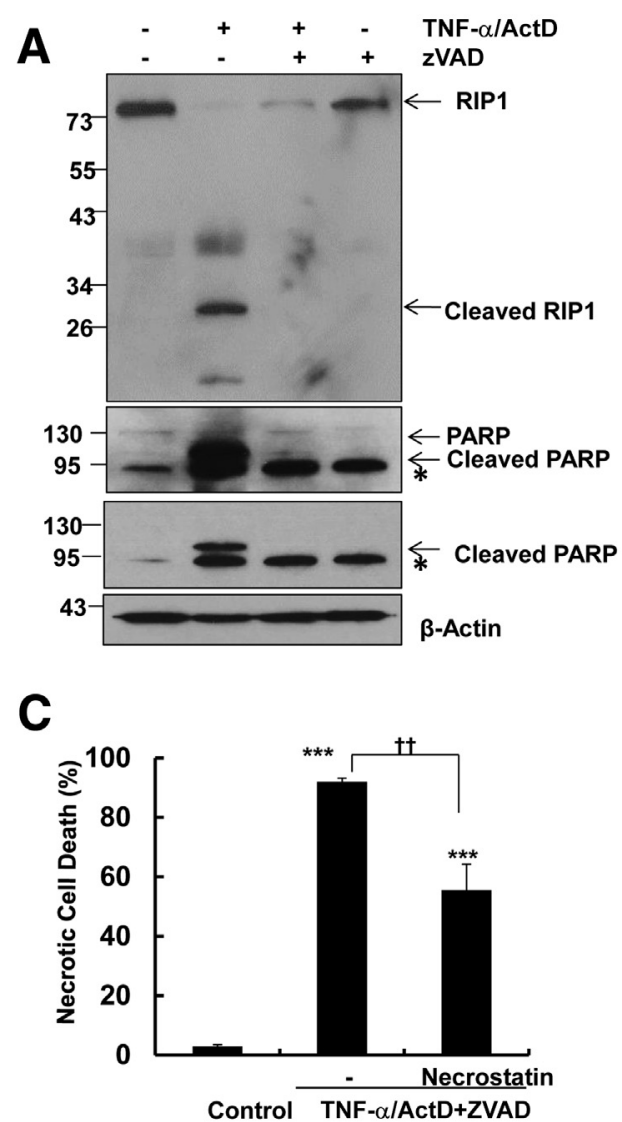

B

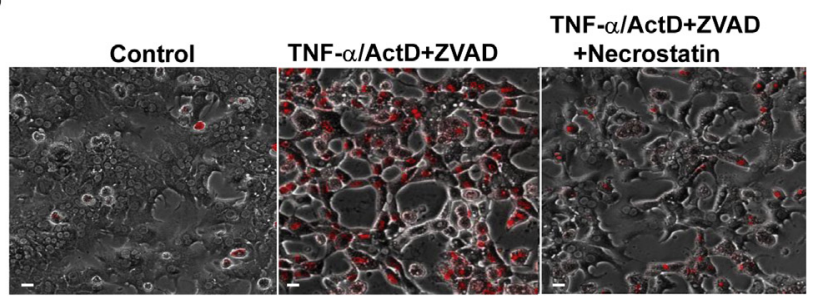

Figure 6 TNF- $\alpha / A c t D+Z V A D$-induced necrosis is partially inhibited by necrostatin in hepatocytes. A: Primary mouse hepatocytes were either untreated (control) or treated with $10 \mathrm{ng} / \mathrm{mL} \mathrm{TNF}-\alpha+0.1 \mu \mathrm{g} / \mathrm{mL}$ ActD in the presence or absence of $50 \mu \mathrm{mol} / \mathrm{L}$ ZVAD for 6 hours, and total cell lysates were subjected to Western blot analysis. All of the gels have been run under the same experimental conditions. Asterisks indicate no specific band. B: Primary mouse hepatocytes were either untreated (control) or treated with $10 \mathrm{ng} / \mathrm{mL} \mathrm{TNF}-\alpha+0.1 \mu \mathrm{g} / \mathrm{mL}$ ActD $+50 \mu \mathrm{mol} /$ L ZVAD in the presence or absence of $40 \mu \mathrm{mol} / \mathrm{L}$ necrostatin for 48 hours. Representative phase-contrast and PI staining overlaid images of hepatocytes are shown. C: Quantification of the PI-positive necrotic cells. Data are expressed as means \pm SEM. $n=3$ independent experiments, and more than 100 cells counted in each experiment. ${ }^{* * *} P<0.001$ versus control; ${ }^{\dagger \dagger} P<0.01$ versus TNF- $\alpha / A c t D+Z V A D$. One-way analysis of variance analysis with Scheffé's post hoc test. Scale bar $=20 \mu \mathrm{m}$ (B). ActD, actinomycin D; PI, propidium iodide; PARP, poly(ADP-ribose) polymerase; RIP, receptor-interacting protein kinase; TNF- $\alpha$, tumor necrosis factor- $\alpha$. neutrophils in the liver under these conditions. We found that LPS/GalN increased the number of Ly6B-positive neutrophils in the liver after 6 hours of treatment, which was not affected by ZVD either at 6 or 24 hours of treatment (Supplemental Figure S2, A and B). Furthermore, inhibition of RIP1 by 7-Nec1 did not affect LPS/GalN/ZVD-induced neutrophil infiltration (Supplemental Figure S2C). Similarly, RIP3 deficiency also had no effect on LPS/GalN/ZVDinduced neutrophil infiltration (Supplemental Figure S3, A and B). Electron microscopy analysis confirmed infiltration of neutrophils and apoptosis in LPS/GalN-treated mouse livers (Supplemental Figure S4). In the presence of ZVD, increased infiltration of red blood cells and neutrophils were readily observed in the mouse livers after treatment with LPS/ GalN for 24 hours. Moreover, hepatocytes also showed extensive vacoulization and swollen mitochondria in LPS/ GalN/ZVD-treated mice regardless of the presence or absence of 7-Nec1. Because LPS/GalN-induced cell death is mainly mediated by the production of cytokines such as TNF- $\alpha$ and IL-1 $\beta$ by macrophages/or Kupffer cells, we next determined the hepatic expression levels of TNF- $\alpha$ and IL-1 $\beta$ under our experimental conditions. We found that the hepatic expression levels of TNF- $\alpha$ and IL-1 $\beta$ were significantly increased in LPS/GalN/ZVD-treated WT mice, but the expression levels were even higher in the presence of 7-Nec1 or in RIP3 KO mice (Figure 8, D and E). Taken together, these results indicate that pharmacologic inhibition of
RIP1 or genetic deletion of RIP3 exacerbated LPS/GalN/ ZVD-induced liver injury by switching necrosis to caspaseindependent apoptotic cell death without affecting neutrophil infiltration. The possible signaling events that regulate apoptosis, necrosis, and autophagy in TNF- $\alpha /$ ActD- or LPS/ GalN-induced liver injury in the presence or absence of a general caspase inhibitor are summarized in Figure 9.

\section{Discussion}

Excess caspase-mediated apoptosis has been implicated in numerous acute and chronic liver diseases. ${ }^{2,4,28,29}$ As a result, pharmacologic inhibition of caspase activity has been considered as a potential therapeutic approach for treating liver diseases with excessive apoptosis such as alcoholic liver disease. ${ }^{28,30}$ TNF- $\alpha$-mediated apoptosis has been well documented to play a central role in acute and chronic liver injuries. ${ }^{4,29}$ When TNF- $\alpha$ binds to its receptor at the plasma membrane of the hepatocytes, it induces the trimerization of these receptors and further recruitment of adaptor molecules, TNF- $\alpha$ receptor-associated death domain protein and RIP1, to form the so-called complex I, which also contains the adaptor protein TNF- $\alpha$ receptor associated factor 2 and E3 ubiquitin ligases cellular inhibitors of apoptosis 1 and 2 (cIAP1, cIAP2), and linear ubiquitin chain assembly complex. Decreased cIAP1, cIAP2, and linear ubiquitin chain assembly 

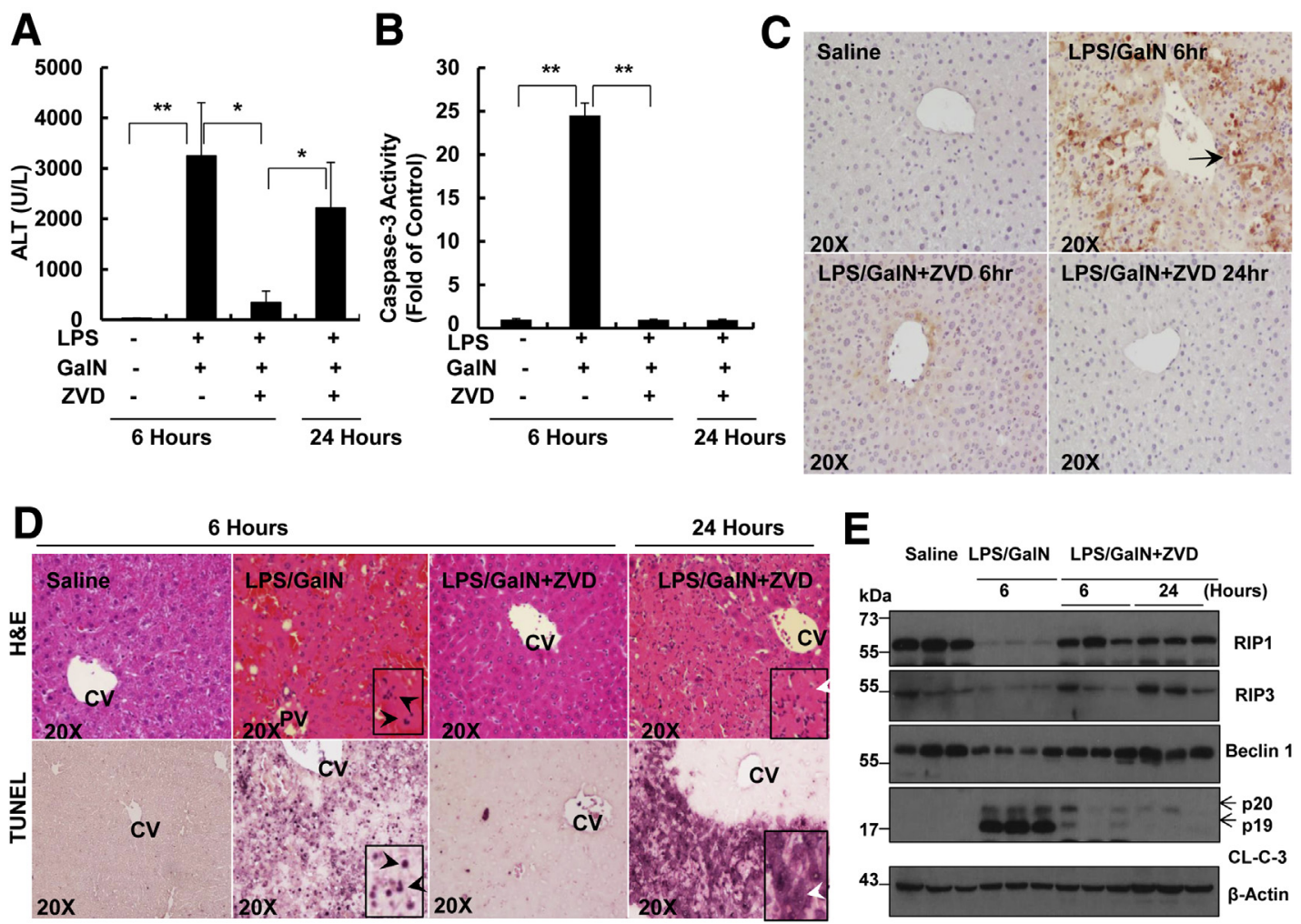

Figure 7 Inhibition of caspase protects against LPS/GalN-induced liver injury during the early phase but induces necrotic cell death during the late phase. A: WT male C57Bl/6 mice were treated with $700 \mathrm{mg} / \mathrm{kg}$ GalN i.p. and $100 \mu \mathrm{g} / \mathrm{kg}$ LPS i.p. for 6 hours. For the ZVD experiments, after the mice were given LPS/ GalN for 3 hours, mice were further given $10 \mathrm{mg} / \mathrm{kg}$ ZVD i.p. for another 3 hours or 21 hours. All of the mice were sacrificed at 6 or 24 hours after the administration of LPS/GalN. A: Serum ALT values were determined and B: Total liver lysates were subjected to caspase-3 activity assay. C: Representative images of liver tissues that were immunostained with a cleaved caspase-3 antibody. Arrows denote cleaved caspase-3-positive cells. D: Representative images of liver tissue H\&E staining and TUNEL staining. Black arrowheads denote apoptotic nuclei. White arrowheads denote necrotic cells. E: Total liver lysates were subjected to Western blot analysis. All of the gels were run under the same experimental conditions. Data are expressed as means \pm SEM. $n=3$ to 7 mice per group. ${ }^{*} P<0.05,{ }^{* *} P<0.01$. One-way analysis of variance analysis with Scheffé's post hoc test. Original magnification: $\times 20$ (C and $\mathbf{D}$, main images); $\times 40$ (D, insets). ALT, alanine aminotransferase; CL-C-3, cleaved caspase-3; CV, central vein; GalN, D-galactosamine; H\&E, hematoxylin and eosin; LPS, lipopolysaccharide; PV, portal vein; RIP, receptor-interacting protein kinase; TUNEL, terminal deoxynucleotidyl transferase dUTP nick end labeling; WT, wildtype; ZVD, N-benzyloxycabonyl-Val Asp-fluoromethyl ketone.

complex activity or increased deubiquitinase cylindromatosis activity results in the deubiquitination of RIP1, which favors the formation of complex II that contains FADD, caspase-8, and cellular FADD-like IL-1 $\beta$-converting enzyme inhibitory protein. ${ }^{7,31-33}$ Activated caspase- 8 in complex II then cleaves the BH3-only protein Bid and the cleaved Bid translocates to mitochondria to trigger the release of cytochrome $c$ and second mitochondria-derived activator of caspase from the intermembrane space of mitochondria, which allows the activation of caspase-9 and downstream caspase-3. Caspase-3 then cleaves inhibitor of caspase-activated DNase, resulting in caspase-activated DNase activation and subsequent degradation of DNA, a hallmark of apoptosis. ${ }^{34}$ It should be noted that RIP3 is also recruited to complex II and that activated caspase-8 cleaves RIP1 and RIP3 to inactivate them. ${ }^{32}$ Therefore, it has been generally agreed on that apoptosis inhibits necroptosis. Indeed, pharmacologic inhibition of caspase-8 triggers RIP1-RIP3-mediated necroptosis in cell culture models. ${ }^{35,36}$ Moreover, the lethal phenotype of caspase- 8 or FADD KO mice can also be rescued by simultaneous deletion of either RIP1 or RIP3., ${ }^{37,38}$ These observations clearly support a cross-regulation of apoptosis and necroptosis.

Here, we demonstrated that TNF- $\alpha$ induced apoptosis in primary cultured mouse hepatocytes, which was completely blocked by a general caspase inhibitor ZVAD at 24 hours. However, hepatocytes died with typical necrotic features after prolonged treatment for up to 48 hours with TNF- $\alpha$ in the presence of ZVAD. Inhibition of RIP1 by necrostatin 1 partially inhibited TNF- $\alpha / Z V A D-i n d u c e d$ necrosis. These findings are generally in agreement with the notion that inhibition of caspases can switch apoptosis to necroptosis. However, only $20 \%$ of TNF- $\alpha / Z V A D-i n d u c e d$ necrosis was reduced by necrostatin 1. Moreover, the levels of RIP3 protein decrease rapidly and are almost undetectable in primary cultured mouse hepatocytes after culturing for 24 hours. ${ }^{39,40}$ Therefore, necrosis induced by TNF- $\alpha /$ ZVAD in primary hepatocytes is likely largely independent of RIP1 and RIP3.

Intriguingly, we also showed that inhibition of caspases protected against LPS/GalN-induced apoptosis and liver injury at an early time point (6 hours), but this protection 

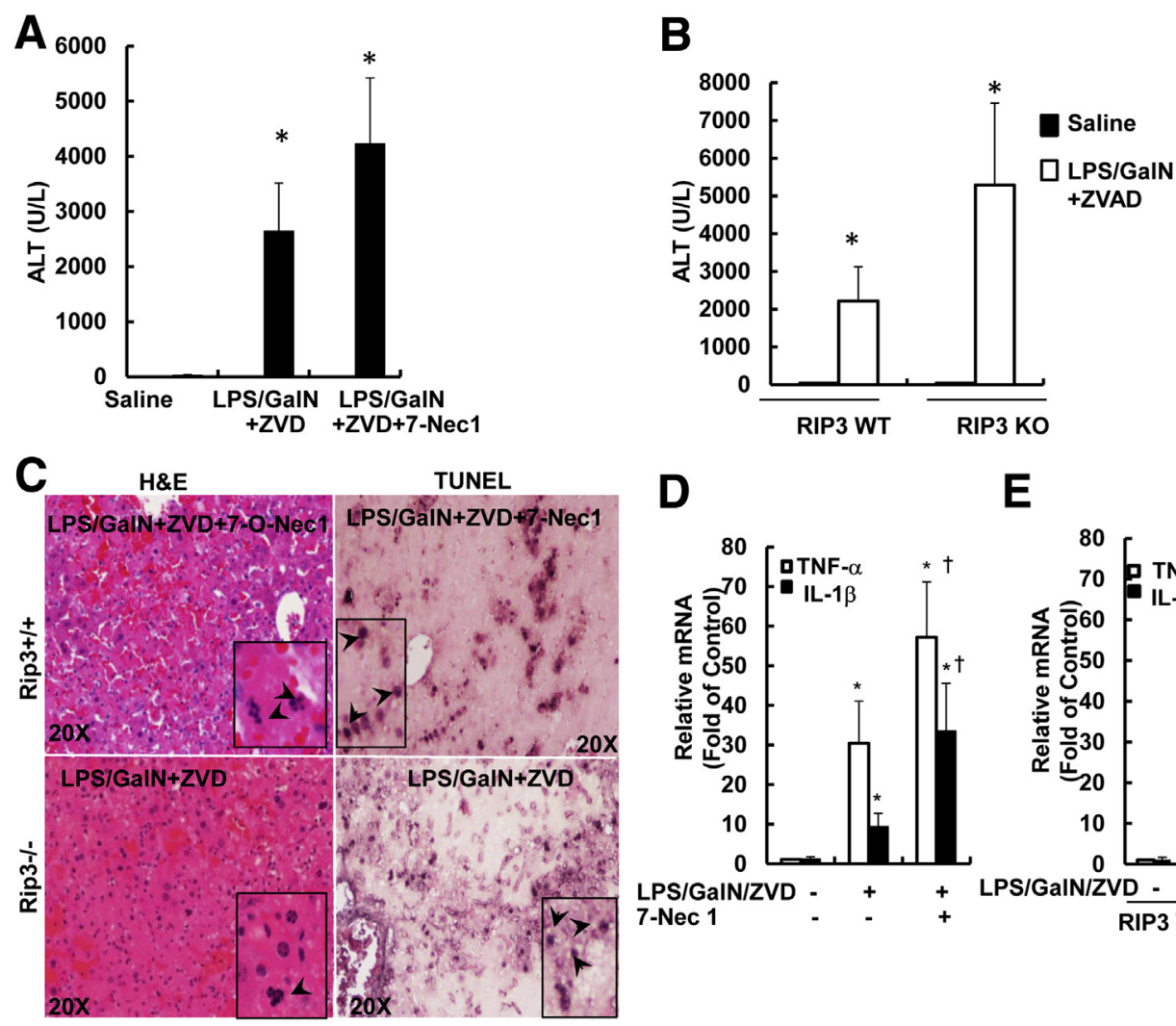

D

E

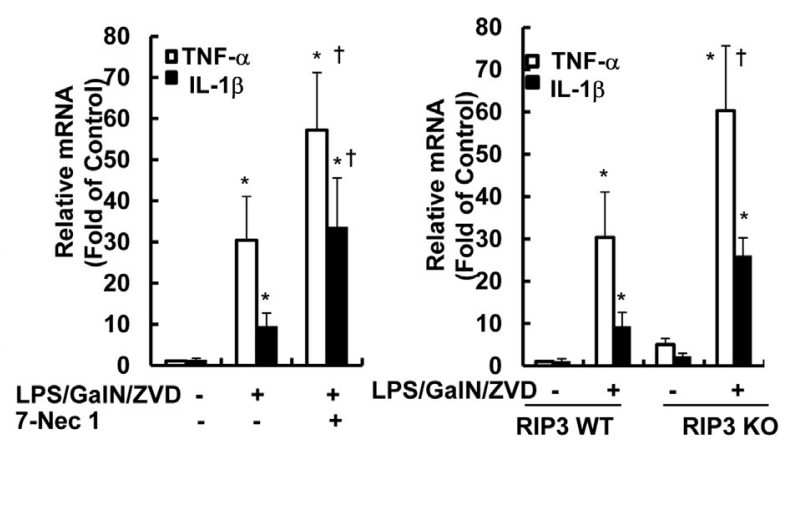

Figure 8 Pharmacologic inhibition of RIP1 or genetic deletion of RIP3 does not protect against LPS/GalN/ZVD-induced late-phase liver injury. A: WT male C57Bl/6 mice were treated with $700 \mathrm{mg} / \mathrm{kg}$ GalN i.p. and $100 \mu \mathrm{g} / \mathrm{kg}$ LPS i.p. for 6 hours. After the mice were given LPS/GalN for 3 hours, mice were further treated with $10 \mathrm{mg} / \mathrm{kg}$ ZVD i.p. for another 21 hours or co-injected with $10 \mathrm{mg} / \mathrm{kg}$ 7-Nec1. All of the mice were sacrificed at 24 hours after the administration of LPS/GalN. A: Serum ALT values were determined. B: WT and RIP3 K0 mice were given LPS/GalN for 3 hours, and the mice were further treated with $10 \mathrm{mg} / \mathrm{kg}$ ZVD i.p. for another 21 hours. All of the mice were sacrificed at 24 hours after the administration of LPS/GalN. B: Serum ALT values were determined. C: Representative images of liver tissue H\&E staining and TUNEL staining. Arrows denote apoptotic nuclei. D and E: Mice were treated as in panels A and B; RNA was extracted from mouse livers and used to measure gene expression by qPCR. Results were normalized to $\beta$-actin and expressed as fold-change compared with control. Data are expressed as means \pm SEM. $n=3$ to 7 mice per group (A and $\mathbf{B}) ; n=4$ to 5 mice per group $(\mathbf{D}$ and $\mathbf{E})$. ${ }^{*} P<0.05$ versus control; ${ }^{\dagger} P<0.05$ versus LPS/GalN/ZVD. One-way analysis of variance analysis with Scheffé's post hoc test. Original magnification: $\times 20$ (C, main images); $\times 40$ (C, insets). ALT, alanine aminotransferase; GalN, D-galactosamine; H\&E, hematoxylin and eosin; K0, knockout; LPS, lipopolysaccharide; qPCR, real-time quantitative PCR; RIP, receptor-interacting protein kinase; TNF, tumor necrosis factor; TUNEL, terminal deoxynucleotidyl transferase dUTP nick end labeling; WT, wild-type; ZVD, N-benzyloxycabonyl-Val Asp-fluoromethyl ketone; 7-Nec1, 7-Cl-0-Nec-1.

was diminished after prolonged treatment for 24 hours by switching apoptosis to necrotic cell death. To our surprise, pharmacologic inhibition of RIP1 or genetic deletion of RIP3, two important proteins that regulate necroptosis, not only failed to protect, but even exacerbated liver injury after the mice were treated with LPS/GalN and a pan-caspase inhibitor. These in vivo findings seemed to be contradictory to our in vitro findings, which showed that necrostatin 1 partially protected against TNF- $\alpha / Z V A D-i n d u c e d$ necrosis. However, in addition to hepatocytes, there are many nonparenchymal cells in the liver that also play important roles in hepatocyte injury. In the context of LPS/GalN-induced hepatocyte death, it is well established that LPS activates Kupffer cells to trigger the production and release of TNF- $\alpha$, whereas GalN deletes UTP in hepatocytes to cause a transient block in transcription and protein synthesis resulting in NF-kb inhibition. ${ }^{26,41}$ Moreover, neutrophils are also known to be recruited to the liver sinusoids after LPS/GalN administration to aggravate liver injury. ${ }^{26,42}$ In fact, apoptotic cell death is the chemotactic signal for extravasation of neutrophils in this model. ${ }^{43}$

It should be noted that we and others recently demonstrated that the expression levels of RIP1 and RIP3 are remarkably higher in immune cells than in hepatocytes. ${ }^{39,44}$ Therefore, it is highly likely that the functions of RIP1 and RIP3 in nonparenchymal cells may play important roles in LPS/GalN/ZVD-induced liver injury, which could be different from their direct role in cultured hepatocytes. Indeed, we found the mRNA levels of TNF- $\alpha$ and IL-1 $\beta$ were significantly higher in the livers of mice treated with RIP1 inhibitor and in RIP3 KO mouse livers after LPS/ GalN/ZVD administration. Although we found that LPS/ GalN/ZVD administration increased hepatic neutrophil infiltration, further administration of the RIP1 inhibitor did not cause significant changes on neutrophil infiltration. Similarly, no difference was found for hepatic neutrophil 


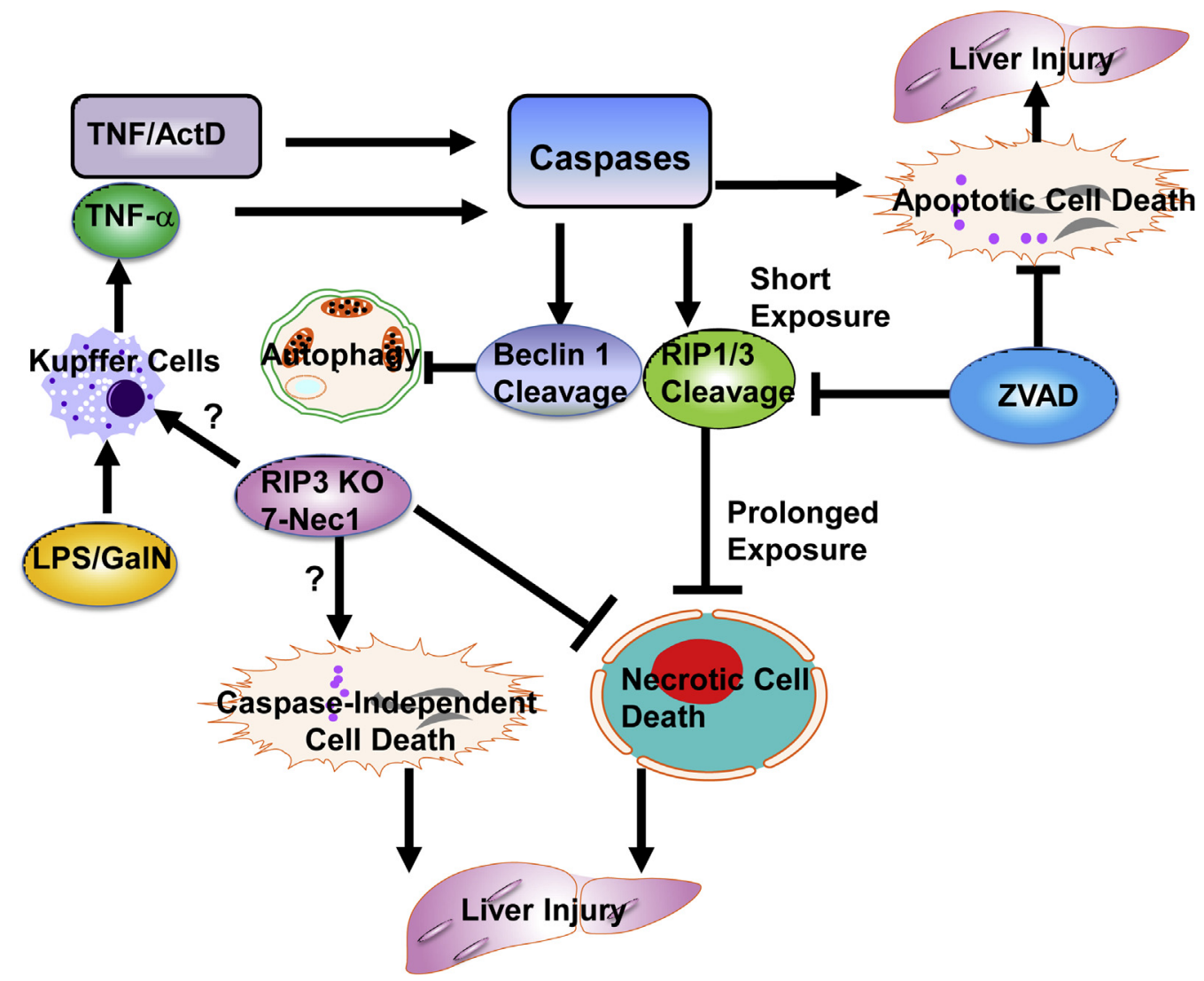

Figure 9 A proposed model of the molecular events in the cross talk of apoptosis, necrosis, and autophagy in TNF- $\alpha$-mediated hepatocyte death and liver injury. In cultured hepatocytes, ActD blocked NF- $\kappa$ B-mediated survival pathways to promote TNF- $\alpha$-induced caspase activation and apoptosis. Activated caspases cleaved RIP1 and RIP3 to inhibit RIP1-RIP3-mediated necrosis. Activated caspases also cleaved Beclin 1 and possibly led to reduced autophagy. Inhibition of caspases by ZVAD blocked TNF- $\alpha$-induced apoptosis after a short exposure but triggered necrosis after prolonged exposure. In the mouse livers, LPS/GalN administration induced TNF- $\alpha$ production through activated Kupffer cells, which then activated caspases and induced apoptosis, resulting in liver injury. Pharmacologic inhibition of caspases blocked apoptosis and liver injury during the early phase but induced necrosis, resulting in liver injury during the late phase. Pharmacologic inhibition of RIP1 or RIP3 K0 mice switched LPS/GalN/ZVD-induced late-phase necrosis to caspase-independent apoptosis by not-yet identified mechanism(s). Pharmacologic inhibition of RIP1 or RIP3 KO mice might promote LPS-mediated Kupffer cell activation to enhance the production of cytokines such as TNF- $\alpha$, which may worsen LPS/GalN/ZVD-induced liver injury. ActD, actinomycin D; GalN, D-galactosamine; K0, knockout; LPS, lipopolysaccharide; RIP, receptor-interacting protein kinase; TNF, tumor necrosis factor; ZVD, N-benzyloxycabonyl-Val Asp-fluoromethyl ketone; 7-Nec1, 7-Cl-0-Nec-1.

infiltration between WT and RIP3 KO mice after LPS/GalN/ ZVD administration. These data may suggest that RIP1 and RIP3 in macrophages/Kupffer cells may be more important than neutrophils in LPS/GalN/ZVD-induced liver injury. Future work to study the role of RIP1 and RIP3 in cytokine production in primary cultured macrophages/Kupffer cells or in isolated neutrophils will be very helpful to test this idea. It should also be noted that RIP3 KO mice are resistant to cerulein-induced pancreatitis or double-stranded RNAinduced retinal generation. ${ }^{36,45}$ Therefore, it is possible that RIP3-mediated necroptosis in tissue injury may also be context and tissue dependent.

Autophagy is a lysosomal degradation pathway that involves the transport of proteins or organelles through the autophagosomes to the lysosomes to form autolysosomes, where the contents are degraded. ${ }^{46}$ Although autophagy is generally thought to be a cell survival pathway against various adverse stresses, ${ }^{9,46}$ it has been reported that a general caspase inhibitor ZVAD induced autophagic cell death in a cell culture model. ${ }^{47}$ However, a later study found that ZVAD did not induce autophagy but instead blocked autophagosome maturation and induced necrosis. Furthermore, activation of autophagy protected against ZVADinduced necrosis. ${ }^{48}$ Here, we found that TNF- $\alpha / Z V A D$ decreased autophagic flux in cultured hepatocytes, and pharmacologic inhibition of autophagy had no effects on TNF- $\alpha / Z V A D-i n d u c e d$ necrosis. Moreover, Atg5 KO hepatocytes were not protected against TNF- $\alpha / Z \mathrm{VAD}$-induced necrosis. These data clearly indicate that TNF- $\alpha / Z V A D-$ induced necrosis is not autophagic cell death.

Perhaps another intriguing finding in this study is that hepatocytes showed typical apoptotic features (fragmented nuclei and nuclei-only TUNEL-positive staining) in the presence of the RIP1 inhibitor after LPS/GalN/ZVD administration, despite the lack of caspase activation. Similar results were also found in the RIP3 KO mouse livers after LPS/GalN/ ZVD administration, suggesting that inhibition of RIP1 or lack of RIP3 switched necrosis to caspase-independent 
apoptosis. The induction of caspase-independent apoptosis with either inhibition of RIP1 or RIP3 KO suggests that caspase-independent apoptosis is less likely to be due to some off-target effects of the RIP1 inhibitor but is indeed associated with the RIP1-RIP3 inactivation. Our observations are different from Ripoptosome-mediated apoptosis, which requires RIP1 kinase activity and caspase- 8 activation because both of them have been blunted in our conditions. ${ }^{49}$ It has been reported that calpain, a calcium-dependent protease, can also induce apoptosis-like cell death independent of caspases ${ }^{50,51}$ However, we did not find significant changes in calpain activity after LPS/GalN/ZVD administration in the presence or absence of the RIP1 inhibitor (data not shown). Moreover, $2 \mathrm{mg} / \mathrm{kg}$ calpeptin (Selleck Chemicals, Houston, TX), a calpain inhibitor, failed to protect against LPS/GalN/ ZVD-induced liver injury (H. Ni and W.X. Ding, unpublished data). How the inhibition of RIP1 or the lack of RIP3 switched LPS/GalN/ZVD-induced necrosis to apoptotic-like cell death remains to be studied in the future.

\section{Conclusions}

Our data demonstrated that inhibition of caspases could protect against TNF- $\alpha$-induced apoptosis in isolated hepatocytes and in mouse livers at earlier time points but inhibition of apoptosis led to necrosis at later time points. The later cell death in the presence of a general caspase inhibitor was not autophagic cell death and was also not dependent on RIP1 and RIP3 in the mouse liver. Our data thus suggest that one should be cautious in treating apoptotic cell death just with caspase inhibitors because, despite their efficacy in preventing apoptosis, these inhibitors may lead to necrotic cell death.

\section{Acknowledgments}

We thank Dr. Vishva M. Dixit (Genentech, San Francisco, CA) for the RIP3 KO mice and the Electron Microscopy Research Lab (EMRL) facility for assistance with the electron microscopy.

H.-M.N., M.R.M., X.C., B.L.W., and W.-X.D. performed experiments; H.-M.N. and W.-X.D. wrote the manuscript; W.-X.D. and H.J. conceived and supervised the study; and all authors read and approved the manuscript.

\section{Supplemental Data}

Supplemental material for this article can be found at http://dx.doi.org/10.1016/j.ajpath.2016.06.009.

\section{References}

1. Luedde T, Kaplowitz N, Schwabe RF: Cell death and cell death responses in liver disease: mechanisms and clinical relevance. Gastroenterology 2014, 147:765-783e4
2. Nagy LE, Ding WX, Cresci G, Saikia P, Shah VH: Linking pathogenic mechanisms of alcoholic liver disease with clinical phenotypes. Gastroenterology 2016, 150:1756-1768

3. Nowak M, Gaines GC, Rosenberg J, Minter R, Bahjat FR, Rectenwald J, MacKay SL, Edwards CK III, Moldawer LL: LPSinduced liver injury in D-galactosamine-sensitized mice requires secreted TNF-alpha and the TNF-p55 receptor. Am J Physiol Regul Integr Comp Physiol 2000, 278:R1202-R1209

4. Ding WX, Yin XM: Dissection of the multiple mechanisms of TNFalpha-induced apoptosis in liver injury. J Cell Mol Med 2004, 8: 445-454

5. Malhi H, Gores GJ, Lemasters JJ: Apoptosis and necrosis in the liver: a tale of two deaths? Hepatology 2006, 43:S31-S44

6. Vanden Berghe T, Linkermann A, Jouan-Lanhouet S, Walczak H, Vandenabeele P: Regulated necrosis: the expanding network of nonapoptotic cell death pathways. Nat Rev Mol Cell Biol 2014, 15: $135-147$

7. Newton K: RIPK1 and RIPK3: critical regulators of inflammation and cell death. Trends Cell Biol 2015, 25:347-353

8. Vandenabeele P, Declercq W, Van Herreweghe F, Vanden Berghe T: The role of the kinases RIP1 and RIP3 in TNF-induced necrosis. Sci Signal 2010, 3:re4

9. Czaja MJ, Ding WX, Donohue TM Jr, Friedman SL, Kim JS, Komatsu M, Lemasters JJ, Lemoine A, Lin JD, Ou JH, Perlmutter DH, Randall G, Ray RB, Tsung A, Yin XM: Functions of autophagy in normal and diseased liver. Autophagy 2013, 9: $1131-1158$

10. Sica V, Galluzzi L, Bravo-San Pedro JM, Izzo V, Maiuri MC, Kroemer G: Organelle-specific initiation of autophagy. Mol Cell 2015, 59:522-539

11. Komatsu M, Waguri S, Ueno T, Iwata J, Murata S, Tanida I, Ezaki J, Mizushima N, Ohsumi Y, Uchiyama Y, Kominami E, Tanaka K, Chiba T: Impairment of starvation-induced and constitutive autophagy in Atg7-deficient mice. J Cell Biol 2005, 169:425-434

12. Ni HM, Boggess N, McGill MR, Lebofsky M, Borude P, Apte U, Jaeschke H, Ding WX: Liver-specific loss of Atg5 causes persistent activation of Nrf2 and protects against acetaminophen-induced liver injury. Toxicol Sci 2012, 127:438-450

13. Kroemer G, Marino G, Levine B: Autophagy and the integrated stress response. Mol Cell 2010, 40:280-293

14. Peter ME: Programmed cell death: apoptosis meets necrosis. Nature 2011, 471:310-312

15. Ni HM, Bockus A, Boggess N, Jaeschke H, Ding WX: Activation of autophagy protects against acetaminophen-induced hepatotoxicity. Hepatology 2012, 55:222-232

16. Amir M, Zhao E, Fontana L, Rosenberg H, Tanaka K, Gao G, Czaja MJ: Inhibition of hepatocyte autophagy increases tumor necrosis factor-dependent liver injury by promoting caspase- 8 activation. Cell Death Differ 2013, 20:878-887

17. Li H, Wang P, Sun Q, Ding WX, Yin XM, Sobol RW, Stolz DB, $\mathrm{Yu}$ J, Zhang L: Following cytochrome c release, autophagy is inhibited during chemotherapy-induced apoptosis by caspase 8mediated cleavage of Beclin 1. Cancer Res 2011, 71:3625-3634

18. Ramachandran A, McGill MR, Xie Y, Ni HM, Ding WX, Jaeschke H: Receptor interacting protein kinase 3 is a critical early mediator of acetaminophen-induced hepatocyte necrosis in mice. Hepatology 2013, 58:2099-2108

19. Ni HM, Woolbright BL, Williams J, Copple B, Cui W, Luyendyk JP, Jaeschke H, Ding WX: Nrf2 promotes the development of fibrosis and tumorigenesis in mice with defective hepatic autophagy. J Hepatol 2014, 61:617-625

20. Ding WX, Ni HM, DiFrancesca D, Stolz DB, Yin XM: Bid-dependent generation of oxygen radicals promotes death receptor activation-induced apoptosis in murine hepatocytes. Hepatology 2004, 40:403-413

21. Williams JA, Ni HM, Ding Y, Ding WX: Parkin regulates mitophagy and mitochondrial function to protect against alcohol-induced liver 
injury and steatosis in mice. Am J Physiol Gastrointest Liver Physiol 2015, 309:G324-G340

22. Scaffidi P, Misteli T, Bianchi ME: Release of chromatin protein HMGB1 by necrotic cells triggers inflammation. Nature 2002, 418 : 191-195

23. Chen X, Ding WX, Ni HM, Gao W, Shi YH, Gambotto AA, Fan J, Beg AA, Yin XM: Bid-independent mitochondrial activation in tumor necrosis factor alpha-induced apoptosis and liver injury. Mol Cell Biol 2007, 27:541-553

24. Ni HM, Bockus A, Wozniak AL, Jones K, Weinman S, Yin XM, Ding WX: Dissecting the dynamic turnover of GFP-LC3 in the autolysosome. Autophagy 2011, 7:188-204

25. Itakura E, Kishi C, Inoue K, Mizushima N: Beclin 1 forms two distinct phosphatidylinositol 3-kinase complexes with mammalian Atg14 and UVRAG. Mol Biol Cell 2008, 19:5360-5372

26. Jaeschke H, Farhood A, Cai SX, Tseng BY, Bajt ML: Protection against TNF-induced liver parenchymal cell apoptosis during endotoxemia by a novel caspase inhibitor in mice. Toxicol Appl Pharmacol 2000, 169:77-83

27. Grasl-Kraupp B, Ruttkay-Nedecky B, Koudelka H, Bukowska K, Bursch W, Schulte-Hermann R: In situ detection of fragmented DNA (TUNEL assay) fails to discriminate among apoptosis, necrosis, and autolytic cell death: a cautionary note. Hepatology 1995, 21:1465-1468

28. Roychowdhury S, Chiang DJ, Mandal P, McMullen MR, Liu X, Cohen JI, Pollard J, Feldstein AE, Nagy LE: Inhibition of apoptosis protects mice from ethanol-mediated acceleration of early markers of CCl4-induced fibrosis but not steatosis or inflammation. Alcohol Clin Exp Res 2012, 36:1139-1147

29. Jaeschke H, Gores GJ, Cederbaum AI, Hinson JA, Pessayre D, Lemasters JJ: Mechanisms of hepatotoxicity. Toxicol Sci 2002, 65: $166-176$

30. Singal AK, Kamath PS, Gores GJ, Shah VH: Alcoholic hepatitis: current challenges and future directions. Clin Gastroenterol Hepatol 2014, 12:555-564. quiz e31-e32

31. Pasparakis M, Vandenabeele P: Necroptosis and its role in inflammation. Nature 2015, 517:311-320

32. Fuchs Y, Steller H: Live to die another way: modes of programmed cell death and the signals emanating from dying cells. Nat Rev Mol Cell Biol 2015, 16:329-344

33. Chan FK, Luz NF, Moriwaki K: Programmed necrosis in the cross talk of cell death and inflammation. Annu Rev Immunol 2015, 33 79-106

34. Enari M, Sakahira H, Yokoyama H, Okawa K, Iwamatsu A, Nagata S: A caspase-activated DNase that degrades DNA during apoptosis, and its inhibitor ICAD. Nature 1998, 391:43-50

35. Sun L, Wang H, Wang Z, He S, Chen S, Liao D, Wang L, Yan J, Liu W, Lei X, Wang X: Mixed lineage kinase domain-like protein mediates necrosis signaling downstream of RIP3 kinase. Cell 2012, $148: 213-227$

36. He S, Wang L, Miao L, Wang T, Du F, Zhao L, Wang X: Receptor interacting protein kinase-3 determines cellular necrotic response to TNF-alpha. Cell 2009, 137:1100-1111

37. Kaiser WJ, Upton JW, Long AB, Livingston-Rosanoff D, DaleyBauer LP, Hakem R, Caspary T, Mocarski ES: RIP3 mediates the embryonic lethality of caspase-8-deficient mice. Nature 2011, 471: $368-372$

38. Zhang H, Zhou X, McQuade T, Li J, Chan FK, Zhang J: Functional complementation between FADD and RIP1 in embryos and lymphocytes. Nature 2011, 471:373-376

39. Dara L, Johnson H, Suda J, Win S, Gaarde W, Han D, Kaplowitz N: Receptor interacting protein kinase 1 mediates murine acetaminophen toxicity independent of the necrosome and not through necroptosis. Hepatology 2015, 62:1847-1857

40. Yang X, Chao X, Wang ZT, Ding WX: The end of RIPK1-RIPK3MLKL-mediated necroptosis in acetaminophen-induced hepatotoxicity? Hepatology 2016, 64:311-312

41. Gujral JS, Farhood A, Jaeschke H: Oncotic necrosis and caspasedependent apoptosis during galactosamine-induced liver injury in rats. Toxicol Appl Pharmacol 2003, 190:37-46

42. Jaeschke H, Farhood A, Smith CW: Neutrophil-induced liver cell injury in endotoxin shock is a CD11b/CD18-dependent mechanism. Am J Physiol 1991, 261:G1051-G1056

43. Jaeschke H, Fisher MA, Lawson JA, Simmons CA, Farhood A, Jones DA: Activation of caspase 3 (CPP32)-like proteases is essential for TNF-alpha-induced hepatic parenchymal cell apoptosis and neutrophil-mediated necrosis in a murine endotoxin shock model. J Immunol 1998, 160:3480-3486

44. Wang S, Ni HM, Dorko K, Kumer SC, Schmitt TM, Nawabi A Komatsu M, Huang H, Ding WX: Increased hepatic receptor interacting protein kinase 3 expression due to impaired proteasomal functions contributes to alcohol-induced steatosis and liver injury. Oncotarget 2016, 7:17681-17698

45. Murakami Y, Matsumoto H, Roh M, Giani A, Kataoka K, Morizane Y, Kayama M, Thanos A, Nakatake S, Notomi S, Hisatomi T, Ikeda Y, Ishibashi T, Connor KM, Miller JW, Vavvas DG: Programmed necrosis, not apoptosis, is a key mediator of cell loss and DAMPmediated inflammation in dsRNA-induced retinal degeneration. Cell Death Differ 2014, 21:270-277

46. Mizushima N, Levine B, Cuervo AM, Klionsky DJ: Autophagy fights disease through cellular self-digestion. Nature 2008, 451:1069-1075

47. Yu L, Alva A, Su H, Dutt P, Freundt E, Welsh S, Baehrecke EH Lenardo MJ: Regulation of an ATG7-beclin 1 program of autophagic cell death by caspase-8. Science 2004, 304:1500-1502

48. Wu YT, Tan HL, Huang Q, Kim YS, Pan N, Ong WY, Liu ZG, Ong CN, Shen HM: Autophagy plays a protective role during zVADinduced necrotic cell death. Autophagy 2008, 4:457-466

49. Tenev T, Bianchi K, Darding M, Broemer M, Langlais C, Wallberg F, Zachariou A, Lopez J, MacFarlane M, Cain K, Meier P: The Ripoptosome, a signaling platform that assembles in response to genotoxic stress and loss of IAPs. Mol Cell 2011, 43:432-448

50. Wolf BB, Goldstein JC, Stennicke HR, Beere H, AmaranteMendes GP, Salvesen GS, Green DR: Calpain functions in a caspaseindependent manner to promote apoptosis-like events during platelet activation. Blood 1999, 94:1683-1692

51. Lankiewicz S, Marc Luetjens C, Truc Bui N, Krohn AJ, Poppe M, Cole GM, Saido TC, Prehn JH: Activation of calpain I converts excitotoxic neuron death into a caspase-independent cell death. J Biol Chem 2000, 275:17064-17071 